\title{
Grupos de geração de renda no Curso Pré- Vestibular Psico-USP: uma experiência de autogestão em um cursinho popular
}

\author{
Felipe Andres Calderon Roa ${ }^{\mathrm{I}, 1}$ e Domenico Uhng Hur ${ }^{\mathrm{II}, 2}$

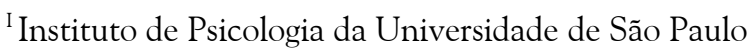 \\ ${ }^{\text {II }}$ Universidade Federal de Goiás
}

\begin{abstract}
Este artigo visa a relatar o projeto de geração de renda com grupos autogestionados realizado no ano de 2001 com alunos desempregados do Curso Pré-Vestibular Psico-USP. A proposta foi experimentar o modelo cooperativo no espaço de um cursinho popular para fomentar a criação de atividades que gerassem renda aos alunos, com o intuito de garantir sua subsistência financeira enquanto estudavam para o vestibular. Apresentamos a experiência de três grupos de trabalho: a) de preparo e comercialização de alimentos; b) de ensino; e c) de produção de itens derivados do papel reciclado. Devido às dificuldades enfrentadas, a participação diminuiu e os dois primeiros grupos dissolveram-se, restando apenas o último. Desse modo, discutimos o processo vivenciado e a parceria estabelecida entre o grupo produtor de papel reciclado e uma multinacional que encomendou a fabricação de dois produtos. Analisamos a experiência dos grupos refletindo sobre as dificuldades de superação da heteronomia como forma de organização instituída na sociedade por modelos instituintes de trabalho, horizontalizados e de autogestão, numa práxis que possa ir além da lógica do capitalismo.
\end{abstract}

Palavras-chave: Economia solidária, Autogestão, Cursinho popular, Psicologia social, Trabalho.

Income generation groups in Psico-USP popular preparatory course for university entrance: an experience of selfmanagement

This article aims to report a project to generate income through self-organized groups conducted in 2001 with unemployed students from Psico-USP popular preparatory course for university entrance. The proposal was to experience the cooperative model in the space of the PPC to promote the creation of activities that generate income to students, in order to ensure their financial support while studying for the exam. We present the experience of three working groups: a) preparation and marketing of food, b) teaching; and c) production of items derived from recycled paper. Due to difficulties, participation decreased and the first two groups dissolved, leaving only the last. Thus, we discuss the process and experienced partnership established between the group producer of recycled paper and a multinational company that commissioned the manufacture of two products. We analyzed the experience of groups reflecting on the difficulties of overcoming heteronomy as a form of organization established in society by instituting models of work, horizontal and self-management, a practice that may go beyond the logic of capitalism.

Keywords: Solidarity economy, Self-management, Popular preparatory course for university entrance course, Social psychology, Work.

$\mathrm{N}$ as últimas duas décadas, no Brasil, constatamos a multiplicação de projetos sociais que visam à democratização do acesso à universidade pública, por meio da criação dos cursinhos populares (Mitrulis \& Penin, 2006). Os cursinhos populares, comunitários ou alternativos são aqueles dirigidos para alunos de baixa renda, que não têm condições de pagar as mensalidades dos "cursinhos tradicionais", e têm como objetivo a inclusão de minorias sociais no ensino superior - sejam alunos pobres, sejam negros ${ }^{4}$, provenientes de movimentos sociais, por exemplo. Os cursinhos alternativos são majoritariamente organizados por

1 Psicólogo graduado pela USP.

2 Psicólogo, mestre e doutor em Psicologia Social pela USP, com doutorado-sanduíche na Universitat Autònoma de Barcelona. Professor Adjunto da Faculdade de Educação da Universidade Federal de Goiás.

3 Chamamos de cursinhos tradicionais aqueles que têm como fim a aquisição de lucros como, por exemplo, Anglo, Etapa, COC, Objetivo etc.

4 Podemos citar, como exemplos de cursinhos para a população negra, o Educafro e o Núcleo da Consciência Negra. 
movimentos sociais e associações estudantis e civis. Eles frequentemente abordam, em suas atividades, discussões político-sociais, além do conteúdo solicitado pelos exames vestibulares.

Contudo, um problema constatado é que o baixo custo das mensalidades ou o fornecimento de bolsas de estudos integrais não são condições suficientes para o aluno terminar seus estudos: há uma alta taxa de evasão, pois existe uma série de outros gastos, como transporte, alimentação, material didático, etc. Em face dessa problemática, a direção do Cursinho Psico-USP idealizou um projeto para lidar com a baixa renda familiar de seus alunos: passou a promover grupos de geração de renda que funcionassem com os preceitos do cooperativismo.

O objetivo deste artigo é relatar a experiência de fomento de grupos de geração de renda autogestionados em um campo que não está diretamente relacionado ao trabalho, mas sim a uma instituição educativa, como um cursinho popular. Dessa forma, este artigo pretende discutir como se desenvolveram os grupos cooperados de geração de renda realizados no Curso Preparatório para o Vestibular Psico-USP, com o intuito de investigar se esse é um modelo de geração de renda que pode contribuir para a subsistência dos alunos de cursinhos populares. Uma vez que, na pesquisa bibliográfica realizada sobre trabalhos acadêmicos relacionados a cursinhos populares (Carvalho, 2006; Mitrulis \& Penin, 2006; Saffiotti, 2008; Santos, 2006; Yamamoto et al., 2006), não encontramos nenhum que abordasse a temática do cooperativismo, buscamos, ao transmitir esta experiência, refletir sobre a conexão entre cursinhos populares e economia solidária.

Procuramos desenvolver os pontos fundamentais sobre a experiência vivida, no que partiremos do problema do desemprego que afeta os estudantes do Cursinho Psico-USP. A seguir, apresentamos uma breve reflexão sobre autogestão e trabalho cooperativo, para depois abordar o processo vivenciado pelos grupos de geração de renda formados, com o fim de refletir sobre o significado dessas experiências no âmbito de um cursinho popular.

Vale ressaltar que essa intervenção teve duração de um ano e meio. Em seu primeiro ano, 2001, foi realizada como atividade obrigatória de estágio ${ }^{5}$ das disciplinas Seleção Profissional I e II, vinculadas ao Centro de Psicologia Aplicada ao Trabalho (CPAT), do quinto ano do curso de graduação em Psicologia do Instituto de Psicologia da USP (IPUSP). Já no primeiro semestre de 2002, último semestre da intervenção, as ações não contaram com supervisão externa. Os autores deste texto fizeram parte do grupo de estagiários que organizou essa atividade em parceria com a coordenação do cursinho.

\section{Entrelaçando o cooperativismo e a questão do desemprego}

\section{O Cursinho Psico-USP e seus alunos}

O Curso Pré-Vestibular Psico-USP é um estabelecimento de ensino coordenado por alunos de graduação do curso de psicologia da Universidade de São Paulo, e, por ser direcionado a pessoas de baixa renda, que não têm condições de pagar um cursinho tradicional, faz parte do movimento dos chamados "cursinhos populares". O Cursinho da Psico, como usualmente é conhecido, tem como objetivo, desde a sua criação, no início de 1999, possibilitar que pessoas pobres aumentem suas chances de ingressar no ensino superior público. Busca, assim, contribuir para a democratização do acesso à universidade pública.

5 Equipe de estágio supervisionada por Fábio de Oliveira e constituída por Felipe Andrés Calderón Roa, Domenico Uhng Hur, Adriana Perassi Bosco, Allan Saffiotti, Juliana de Oliveira Brás e Matheus Machado Oliveira. 
Dentro desse propósito, existe um processo de seleção socioeconômica para a escolha de seus alunos: as vagas são concedidas aos candidatos que apresentam menor renda per capita. Tal critério de seleção sempre traz um desafio a ser enfrentado, pois, ao selecionar os quatrocentos alunos com menor renda, o cursinho acaba por, consequentemente, escolher alunos que não têm condições de pagar a taxa de setenta reais ${ }^{6}$ destinada a cobrir os gastos operacionais da instituição - como salários de funcionários e professores, material didático, gastos com conservação do prédio etc. Tendo em vista as dificuldades dos alunos em pagar essa taxa, o Curso Pré-Vestibular Psico-USP, no ano de 2001, buscou amenizar o problema fornecendo bolsas que concediam descontos integrais e parciais, de acordo com seus critérios socioeconômicos. Essa ação, porém, não se mostrou eficaz, pois não atendeu à grande demanda de alunos que necessitavam desse benefício. Mesmo os alunos bolsistas apresentavam dificuldades para se manter estudando, pois tinham outros gastos, não cobertos pela bolsa, como o valor do transporte para chegar ao cursinho, alimentação, entre outros.

Para lidar com as dificuldades econômicas dos alunos, os estagiários do Centro de Psicologia Aplicada ao Trabalho (CPAT) e a equipe coordenadora do cursinho elaboraram uma proposta de geração de renda referenciada nas diversas experiências de formação e estudo de grupos cooperativos realizados na Universidade de São Paulo. Por meio dessa proposta, seus idealizadores pretendiam envolver os alunos do cursinho interessados em uma atividade econômica que, gerida e construída por eles, permitisse o estabelecimento de relações horizontais de poder e a escolha de uma atividade com a qual apresentassem mais afinidade. Sendo eles mesmos responsáveis pela administração do tempo e do processo produtivo, haveria maior flexibilidade (manejo) dos horários de trabalho, o que poderia facilitar a organização dos alunos, ao permitir conciliar as atividades de geração de renda com as atividades de preparação para o vestibular.

\section{Autogestão, autonomia e trabalho cooperativo}

A questão com que iniciamos este tópico é: por que o trabalho cooperativo em um cursinho popular? Por que não estabelecer um projeto de geração de renda nos moldes da produção capitalistas?

Consideramos que o trabalho de geração de renda com base na autogestão tem grande compatibilidade política com os preceitos dos cursinhos populares, pois também visa à "inclusão social" - nesse caso, econômica - a partir de princípios políticos afins, que entendemos como a tentativa da horizontalização das relações de poder e a propagação de uma concepção de mundo mais associativista, como alternativa à concepção competitiva do mundo capitalista.

Com base nas reflexões de Singer (2000) e de Oliveira (2007), compreendemos que as experiências de trabalho com cooperativas buscam a autogestão compromissadas com o que o filósofo Cornelius Castoriadis entende por autonomia. A autonomia é a criação de "leis" (nomos) pelo próprio coletivo, em que este não deve ser subordinado à heteronomia instituída e que, pela sua própria gestão, deve se autocriar e se autoinstituir. De acordo com Castoriadis (1992),

a criação pelos gregos da filosofia e da política é a primeira emergência histórica do projeto de autonomia coletiva e individual. Se quisermos ser livres devemos fazer nosso nomos. Se quisermos ser livres, ninguém deve poder dizer-nos o que devemos pensar (p. 138).

Tal concepção influenciou diversas correntes da Análise Institucional francesa ${ }^{7}$, que têm como objetivo geral promover processos de autoanálise e autogestão (Baremblitt, 2002)

6 Taxa mensal cobrada no ano de 2001.

7 Como também influenciou a Análise Institucional brasileira e argentina. 
com os fins de perseguir o projeto da autonomia social. Desse modo, consideramos que uma aproximação possível entre os preceitos do cooperativismo e dos cursinhos populares é essa busca de divisão de poderes na sociedade, que chamamos de busca pela autogestão, e o exercício de autoanalisar os processos sociais e coletivos em que estão inseridos, ou seja, o exercício de uma autoanálise.

Contudo, o projeto de uma autonomia social é algo muito complexo, pois

de una manera concisa podemos afirmar que asistimos a la dominación integral del imaginario capitalista: centralización de la economía, expansión indefinida y pretendidamente racional de la producción, del consumo y de las diversiones más o menos planificados y manipulados (Castoriadis, 1994, p. 106).

Ou seja, há uma dominação do imaginário capitalista que propaga uma lógica de poderes assimétrica, que é o que entendemos que a economia solidária visa a combater e aparece como alternativa.

Ante as vicissitudes do capitalismo, o trabalho cooperativo autogestionário aparece como um outro modelo político de gestão em relação às formas heterônomas instituídas de trabalho. O cooperativismo, segundo o analista institucional René Lourau (1979):

é um conceito produtivista surgido das contradições do modo de produção capitalistas [...] A autogestão se refere a uma racionalização do trabalho e, por extensão, como autogestão generalizada, a uma racionalização da vida social [...] a autogestão outorga um conteúdo de socialização levado até o limite da racionalização; por conseguinte um conteúdo de luta contra o centralismo e contra toda planificação constituída pela propriedade privada de uma casta de profissionais da economia e da política (p. 201).

Historicamente, os conceitos que inspiraram a economia solidária foram desenvolvidos pelo socialismo utópico, com base nas reflexões de Charles Fourier e Robert Owen (Veronese \& Guareschi, 2005) e foram trazidas ao Brasil no começo do século XX pelos imigrantes europeus (Singer, 2002). Atualmente, no Brasil, Paul Singer (2000), uma das maiores referências da economia solidária no país, nos ensina que, nas relações de produção em autogestão, há posse coletiva dos meios de produção pelos participantes, uma gestão democrática por participação direta ou representativa (se o número de membros é elevado) e a repartição da receita líquida com base em critérios discutidos pelo conjunto. Essa democratização e a cooperação no processo de produção também implicam mudanças subjetivas de seus participantes, que podem passar a entender o trabalho além das diretrizes impostas pelo capital, vivendo, assim, outro regime, baseado em relações de solidariedade e não de competição. Esse aspecto da relação entre estrutura de trabalho e modos de subjetivação (Nardi et al., 2006) é de suma importância, visto que o trabalho em grupos cooperados não se alicerça apenas em procedimentos organizacionais, mas também em uma transformação subjetiva, enfim, em uma transformação psicossocial. Conforme Leny Sato (1999), o grande desafio para a psicologia social no trabalho com cooperativas

é criar um novo modo de relacionar-se, de ver o trabalho e a vida, que opere através de uma outra racionalidade, que não a instrumental, a partir das pessoas que somos, das experiências de vida que temos e da sociedade onde vivemos [...].

Consideramos que a autogestão é uma práxis política (Lechat \& Barcelos, 2008) no que se refere a uma democratização nas relações de trabalho e de produção, em que o objetivo a se perseguir são relações mais horizontais no ambiente de trabalho, em que haja participação coletiva nas deliberações dos processos e, conforme Castoriadis (1983), uma supressão da hierarquia de salários por posto funcional. A implicação dos participantes nas deliberações e na gestão da organização desterritorializa as relações instituídas de trabalho na já conhecida 
dominação de um patrão sobre seus empregados, e aproxima o grupo de uma gestão coletiva em que todos, ao mesmo tempo, são senhores e são submetidos ao coletivo.

Além do caráter político transformador, as cooperativas de trabalho também se apresentam como alternativas em momentos de crise relacionados à desaceleração da economia. O processo de desindustrialização das décadas de 1980 e 1990, somado à subsequente redução dos postos de trabalho, acarretaram desemprego em massa e acentuada exclusão social, contribuindo para que a economia solidária ressurgisse como alternativa concreta no Brasil (Singer, 2002, p. 122). Dentro das universidades, grupos multidisciplinares formados por docentes, funcionários, pós-graduandos e graduandos prestam apoio às cooperativas e contribuem para o seu processo de consolidação por intermédio das incubadoras tecnológicas de cooperativas populares (ITCPs), dando assistência jurídica, contribuindo com o processo de formação e fortalecendo as redes de intercâmbio entre as cooperativas, dentre outras ações.

Tendo em vista tais aspectos da economia solidária, notadamente a busca pela autonomia social e a constituição de relações solidárias, consideramos este um campo profícuo para atividades de geração de renda e de formação psicossocial em cursinhos populares.

\section{Grupos de autogestão no cursinho}

\section{As primeiras reuniões}

Logo após a organização do projeto pela coordenação do cursinho e pela equipe do CPAT, tratou-se de convidar os alunos do cursinho interessados para a primeira reunião, que ocorreu em abril de 2001 e contou com a participação de oitenta cursistas - um número superior ao esperado.

Nesse primeiro encontro, o grupo de estagiários do CPAT apresentou o projeto, apontando uma possibilidade de trabalho e geração de renda que pretendia questionar e romper com os modelos tradicionais de organização do trabalho, com o intuito de amenizar o problema do desemprego vivido pelos cursistas. Os estagiários apresentaram a proposta de formação dos grupos e investigaram o conhecimento prévio dos cursistas sobre os preceitos cooperativistas. Das diversas representações expressas pelos alunos, chamou-nos a atenção o entendimento de um aluno que disse que "[...] a cooperativa é o espaço em que você trabalha, mas não ganha nada, nem os benefícios, nem o décimo terceiro [...]". Consideramos, que essa representação, comumente manifesta quando se discute o cooperativismo, deve-se à apropriação do modelo jurídiconormativo das cooperativas por empresas que apenas têm como intuito arrematar maior isenção tributária. Essas "coopergatos" ou "cooperfraudes", como normalmente são conhecidas, além de pagarem menos impostos ao governo, também propiciam menos benefícios aos trabalhadores, não dispondo de uma gestão participativa, democrática e com base na economia solidária (Oliveira, 2007). Na apresentação do grupo de estagiários, tentou-se desmistificar a significação negativa atribuída às cooperativas e privilegiou-se a proposta de um trabalho autônomo em grupo, palavra-chave desse primeiro encontro e do projeto como um todo.

Em seguida, passou-se a discutir a questão do trabalho em grupo, e os cursistas abordaram os aspectos positivos e negativos de se trabalhar coletivamente. Em relação aos aspectos positivos, os cursistas ressaltaram: maior capacidade de trabalho, diversificação de atividades e produtos oferecidos, divisão mais racional das tarefas e do trabalho, colaboração na hora da produção e consequente maior ganho. Alguns também enalteceram a cooperação entre pessoas que se encontram em dificuldades financeiras. Dentre os aspectos negativos do trabalho 
em grupo, surgiram: possível desorganização do coletivo, problemática da divisão dos lucros, conflitos ao trabalhar com outros e, finalmente, a desconfiança que o outro provoca, podendo afetar inclusive o bom andamento do trabalho. A divisão dos ganhos foi um dos pontos em destaque, apresentando uma dupla faceta. A positiva referia-se à maior facilidade na obtenção de recursos e a negativa referia-se à problemática da divisão do arrecadado.

Essa primeira reunião desfez a expectativa inicial de alguns cursistas, que esperavam vagas de empregos dentro dos moldes tradicionais da lógica de mercado, hierarquizada e vertical. A perspectiva de criar um empreendimento em grupo, dentro dos valores da autogestão, não agradou à maioria. $\mathrm{O}$ mal-estar e o desapontamento estavam implícitos e aproximadamente três quartos dos presentes não retornaram às outras reuniões. Um clima misto marcou esse primeiro encontro, pois alguns pareciam bem animados, enquanto outros, bem desmotivados com a nova empreitada.

Já a segunda reunião, realizada uma semana depois, contou com a participação de vinte cursistas. Foram discutidas atividades de geração de renda que poderiam ser oferecidas pelos cursistas para a comunidade do entorno, assunto que foi abordado superficialmente na primeira reunião. Emergiram dos participantes ideias variadas e diversas, como: organização de eventos, visitas monitoradas a estabelecimentos públicos, preparação de cestas de café da manhã, serviço de telemensagens, formação de banda musical, confecção e venda de produtos alimentícios, reciclagem de papel e oferecimento de aulas particulares. Algumas ideias mostraram-se inviáveis em virtude de sua grande magnitude e dos poucos recursos disponíveis para a realização. Outras iniciativas foram descartadas após a avaliação do grupo, que entendeu serem de difícil retorno financeiro. Dessa forma, depois de mais alguns encontros, o grupo construiu um consenso, chegando a três tipos de atividades de geração de renda: a) o de preparo e comercialização de alimentos, que recebeu o nome de "grupo de comida"; b) o grupo de ensino, que pretendia oferecer aulas particulares e 3) o grupo de produção de papel reciclado e derivados.

\section{A divisão dos grupos}

Considerando a existência e a constituição desses três grupos de trabalho, cada cursista optou pela tarefa com que tinha mais afinidade. Inicialmente, apoiada pelos cursistas, a intenção dos estagiários era de que um único grupo realizasse todas as distintas atividades de geração de renda, compartilhando as reuniões de planejamento e usufruindo de um único fundo comum; ou seja, o objetivo era que todos os recursos adquiridos pelas três atividades de geração de renda fossem destinados a esse fundo a ser compartilhado por seus integrantes. Porém, os diferentes ritmos de trabalho de cada grupo e a diferença entre as atividades realizadas acabaram por fortalecer um sentimento de desigualdade entre os membros: alguns se sentiam trabalhando mais do que outros. Para resolver esse mal-estar, o coletivo decidiu se subdividir em três frentes, separando os caixas e realizando reuniões específicas para cada grupo. Porém, mesmo assim, foram mantidas as reuniões do "grupão" com todos os participantes - espaço esse reservado para discussóes do projeto como um todo e para a formação em autogestão e cooperativismo. 


\section{O curso de cooperativismo}

Com o intuito de apresentar e discutir os preceitos da economia solidária, foi proposto aos cursistas um "curso" que trataria, em três encontros - e, portanto, de forma breve -, da história do cooperativismo. O curso foi ministrado por uma das estagiárias do CPAT, que, na época, fazia parte da ITCP-USP. A proposta do curso foi a de introduzir, com base na história do cooperativismo, alguns conceitos básicos que pudessem ser discutidos pelos alunos cursistas. Por meio de exemplos práticos, foram apresentadas vantagens e dificuldades encontradas nas práticas de trabalho em autogestão.

Nos encontros do curso, a autogestão suscitou discussões sobre a organização vertical e horizontal do poder em nossa sociedade. Foram também amplamente discutidos alguns mecanismos de exclusão ou inclusão marginal, dentro e fora do mercado de trabalho. Os alunos mostraram-se interessados e muito participativos, entrelaçando o tema apresentado com outras questões pertinentes à discussão como: a educação oficial (ou sua falta) utilizada como instrumento de poder, a apropriação indébita do termo cooperativa por modelos de organizações convencionais hierarquizadas e a discussão sobre o crescimento do modelo de autogestão e suas possibilidades e limitações.

\section{O grupo de preparo e comercialização de alimentos}

O objetivo inicial dessa frente de trabalho foi produzir itens alimentícios para o varejo e para lanchonetes e restaurantes da região do entorno do Instituto de Psicologia da USP. Esse grupo, formado por mulheres, tinha a intenção de produzir marmitas, sanduíches e doces em geral, como bolos, trufas etc.

Ao constatarem que não dispunham de capital de investimento, perceberam que não poderiam produzir o quanto pretendiam, nem ao menos poderiam ter uma infraestrutura coletiva, como um espaço fixo de trabalho, cozinha e materiais comuns, como fogão industrial, freezer, panelas, mesa etc. Dessa forma, o grupo decidiu realizar atividades de pequeno porte, que dispensariam o uso de tal instrumental, com uma produção individualizada e em menor escala.

Nesse sentido, as participantes decidiram produzir bolos e doces para vender no espaço comum do IPUSP e em outros lugares da universidade. Cada uma produziu os alimentos individualmente em suas casas, sendo esse o primeiro grupo a iniciar suas atividades. A primeira atividade de comercialização (e geração de renda) deu-se em um evento extracurricular do cursinho, em que o grupo vendeu grande parte do produzido.

Com o intuito de gerar mais recursos, o grupo resolveu reinvestir a verba arrecadada organizando a rifa de uma cesta de produtos alimentícios. A ideia foi bem-sucedida, o que fez com que os recursos iniciais fossem ampliados significativamente. A data escolhida para o sorteio da rifa, uma festa, também serviu de oportunidade para ampliar a venda dos produtos alimentícios preparados por esse grupo, que, com essa ação, aumentou ainda mais a sua renda.

Com o aumento da renda, novas questões se impuseram e a de maior expressão foi aquela vinculada à distribuição dos recursos (a retirada) pelos membros do grupo. A falta de experiência nessa discussão e a dificuldade em aprofundar o tema com o grupo acabaram por propiciar desentendimentos, mal-estares e conflitos, pois parte significativa dos integrantes sentia e expressava que "[...] tinha aquela que fazia mais enquanto a outra fazia menos [...]". Brigas, acusações, desavenças e atritos se intensificaram, produzindo um esvaziamento do grupo. A desarticulação do grupo e a dificuldade em se encontrarem acabaram dificultando o diálogo e encerrando as atividades do grupo de preparo e comercialização de alimentos. Suas integrantes desistiram desse projeto, que durou cerca de quatro meses, e acabaram por migrar para os outros dois grupos. 


\section{O grupo de ensino}

O grupo de ensino tinha como proposta oferecer aulas particulares para alunos do ensino básico que necessitavam de auxílio extra para desenvolver suas atividades escolares cotidianas. Com isso, os cursistas, ao mesmo tempo em que se preparavam para os vestibulares, compartilhariam o conhecimento adquirido exercendo uma atividade remunerada.

O grupo reuniu-se semanalmente e, nessas reuniões, surgiu a angústia decorrente da inexperiência em lecionar aulas. Nele havia apenas duas pessoas com pequena experiência em ensino e os demais não tinham nenhuma. Assim, decidiu-se utilizar os próprios recursos do grupo para promover a formação dos futuros "professores particulares". Um minicurso de formação de professores particulares foi ministrado pelos integrantes do grupo que tinham experiência na área.

Após o minicurso, os participantes estabeleceram uma série de tarefas, realizando os acertos finais para o início do trabalho; foi deliberado que a remuneração seria igual para todos, e os participantes mantiveram uma das ideias iniciais do projeto, buscando criar um "fundo comum de solidariedade" para os três grupos, um fundo que auxiliaria cada grupo a realizar suas atividades em períodos de necessidade e escassez financeira.

As tarefas foram divididas entre os membros do grupo, porém pouco foi realizado de fato. O grupo acabou se desarticulando; alguns membros saíram e outros se desinteressaram. A chegada do vestibular e a necessidade de encontrar uma atividade remunerada em curto prazo contribuíram para a desagregação do grupo, que teve duração de cinco meses.

\section{Grupo de produção de papel reciclado e derivados}

No conjunto das atividades sugeridas no primeiro encontro, a produção de materiais provenientes da reciclagem de papel ganhou destaque. Os relatos de uma cursista, que aqui chamaremos de Andreia, que já confeccionava tais produtos, contribuíram para a boa aceitação dessa sugestão pelos demais participantes na reunião. Seu vasto conhecimento referente à técnica de produção e sua experiência relacionada às vendas do produto influenciaram significativamente a formação desse grupo de geração de renda. Andreia apresentou portaretratos, cadernos, blocos de nota, álbuns de fotografia etc., como possibilidades de produtos a serem confeccionados por meio do processo de reciclagem.

O grupo, em seu início, contou com a participação ativa de oito membros, que se reuniram semanalmente, intercalando discussões conceituais sobre cooperativismo com assuntos de ordem prática, como o processo de aprendizagem e a manufatura do papel reciclado.

$\mathrm{Na}$ fase de estruturação inicial, como estratégia elaborada pelo grupo, foram realizadas oficinas abertas para que outras pessoas pudessem conhecer o processo de reciclagem, apresentando o novo grupo de trabalho para os demais alunos do curso pré-vestibular e convidando os interessados a participarem dessa atividade de geração de renda, o que agregou novos componentes.

No mês de julho, o grupo se deparou com a saída de alguns membros e a permanência de outros em condições particulares. Alguns membros se afastaram por apresentar interesse em outros grupos de trabalho e outros, devido ao ingresso em instituições de ensino de nível superior. Andreia também se encontrava nessa condição, porém, sua entrada no curso técnico de enfermagem não a afastou totalmente do grupo. Com a diminuição do número de participantes, tornou-se fundamental promover a capacitação de novos membros que dessem conta do processo básico da produção (feitura das folhas de papel reciclado) e do processo complexo e trabalhoso de criação, visando à continuidade do grupo. Tendo essa discussão em 
vista, o grupo organizou seu tempo dividindo os trabalhos em dois momentos: capacitação técnica e produção. Devido ao tempo escasso destinado à produção, o grupo considerou importante voltar-se para a confecção de produtos com maior valor agregado.

No final do ano, o grupo obteve a informação, por intermédio de um dos alunos cursistas, funcionário de uma multinacional, que sua empresa estava interessada em estabelecer uma parceria com alguma entidade social. Essa empresa, ao receber orientações da matriz norte-americana, procurou investir em um empreendimento social que pudesse ser utilizado como marketing social e, por meio desse contato, interessou-se pelas atividades de geração de renda ligadas à reciclagem de papel do Curso Pré-Vestibular Psico-USP. Essa aproximação acabou por estabelecer uma parceria que possibilitou à empresa associar sua marca a uma entidade de ensino vinculada à USP e reduzir parte de sua produção de lixo, pois reciclaria suas sobras de papel sulfite, antes descartadas no lixo comum. Essas sobras seriam recolhidas pelo grupo de cursistas e serviriam de matéria-prima para a produção de materiais de escritório para a própria empresa, confeccionados por meio do processo de reciclagem. Dessa forma, o grupo teve a necessidade de estabelecer uma organização produtiva que atendesse às demandas dos novos parceiros e, também nesse período, teve a necessidade de ter um nome oficial, batizandose de Grupo Papel Natural (GPN).

Após algumas reuniões com a instituição parceira, o GPN estabeleceu o compromisso pelo recolhimento semanal dos sacos que conteriam folhas de papel sulfite, dentro de um esquema de coleta seletiva a ser implementado pela empresa, e também ficou responsável pela criação e pela apresentação de produtos que tivessem em sua composição o papel reciclado. Em contrapartida, a empresa remuneraria o GPN pelo trabalho de produção e internamente instituiria a coleta seletiva de papel, ao estimular o consumo consciente e a diminuição do lixo produzido pelos seus funcionários. Para a implementação dessa "nova cultura" na empresa, foram realizadas minipalestras e pequenas oficinas, com o intuito de sensibilizar os funcionários para a importância da coleta seletiva e da reciclagem. Nessas oficinas, os funcionários experimentaram o processo de reciclagem, confeccionando uma nova folha a partir de folhas inutilizadas nos diversos escritórios da empresa.

Nesse período, o grupo confeccionou e apresentou três possíveis produtos a serem comercializados para a empresa: um porta-lápis contendo um compartimento para a colocação de cartão de visita, um bloco de anotações contendo amarras artesanais e pequenas cadernetas de anotações. Como resultado desse processo, foram encomendadas 100 cadernetas e 400 blocos de anotações de dois modelos diferentes.

A encomenda da multinacional, amplamente comemorada pelo grupo, teve como consequência direta a garantia de renda, já que ela saía do plano das ideias e se realizava em sua concretude por meio dessa encomenda. Nesse labor, o grupo pôde perceber com maior clareza os resultados de seu trabalho e as potencialidades de trabalhar em um modelo de produção coletiva.

O processo de produção foi garantido e o prazo de entrega dos produtos foi atendido, porém muitas foram as dificuldades para o cumprimento do compromisso estabelecido com a empresa. Problemas por não terem um local de trabalho fixo, dificuldades de horários, dificuldades financeiras e falta de comunicação entre os integrantes foram alguns dos motivos que contribuíram para a fragilização das relações no grupo de trabalho.

De qualquer forma, essa encomenda foi considerada um marco importante para o grupo. Contudo, após sua entrega para a multinacional, o GPN demonstrou uma relação frágil entre seus participantes, mesmo com perspectivas de novas encomendas, e acabou por se desfazer. Tentativas posteriores de retomar esse grupo foram feitas, sem sucesso. Após um ano e meio, devido às dificuldades apresentadas, o GPN encerrou suas atividades. 


\section{Considerações Finais}

No presente artigo, buscamos apresentar uma experiência de grupos de geração de renda baseada na autogestão e desenvolvida com alunos de baixa renda de um cursinho comunitário, com o intuito de apresentar reflexões referentes à possibilidade de essa iniciativa ser um dispositivo político-econômico interessante a esse tipo de organização.

Primeiramente, discutimos que a busca por autonomia, conforme entende o filósofo Castoriadis (1994), é um dos pontos principais que ligam politicamente a economia solidária a projetos sociais, como os cursinhos populares - justificando, assim, a pertinência de uma divisão de poderes, baseada na autogestão, nos fazeres dos grupos de geração de renda do cursinho.

Em seguida, apresentamos como se desenrolou o processo em si. Por um lado, pensando em termos de constituição de um programa de geração de renda estruturado e consistente, pode-se entender o projeto como um "fracasso", visto que o grupo de comida teve uma curta duração, o grupo de ensino também teve curta duração, não chegando a trabalhar com o público externo, e o GPN desarticulou-se no fim da sua primeira encomenda. Contudo, não consideramos que o processo em si foi um "fracasso", pois acarretou fazeres e mudanças nas práticas e concepções de poder de alguns cursistas participantes, gerando transformações localizadas, por mais que não se tenha constituído um modelo orgânico de geração de renda para cursinhos populares.

Para falar dessas transformações localizadas, vamos retomar o que ocorreu nos grupos: por que o GPN apresentou atividade mais consistente que os outros dois grupos? Por que o grupo de comida e o grupo de ensino rapidamente se desagregaram?

Primeiramente, surgiu algo não esperado pelos estagiários: a cisão do projeto em três grupos, divisão realizada pelos cursistas devido a uma justificativa pragmática de operacionalização das tarefas. Consideramos que isso causou dificuldade inicial para os estagiários, pois estes tiveram que se dividir para poderem acompanhar as atividades dos três grupos.

Em relação ao grupo de comida, houve uma euforia inicial pelo trabalho e pelas vendas realizadas, mas que logo deu lugar aos conflitos internos e à sensação de injustiça, de que alguns trabalhavam menos do que outros, culminando na fragmentação do grupo. Uma hipótese que levantamos é que talvez o início das atividades tenha sido precoce, pois o trabalho de formação nos preceitos da economia solidária foi, de certa forma, descuidado; por exemplo, quando foi organizado o curso de cooperativismo, o grupo de comida já estava perdendo a coesão. Entendemos, então, que, apesar de o grupo já contar com conhecimento técnico para seu labor, não tinha as concepções da economia solidária internalizadas, conhecimento que talvez pudesse ter diminuído os conflitos que se seguiram e garantido a continuidade do grupo por mais tempo.

No grupo de ensino, consideramos que ocorreu um processo inverso ao do grupo de comida: não havia conhecimento técnico do labor e houve certa apropriação das concepções políticas da economia solidária. A pouca experiência em lecionar aulas trouxe insegurança e angústia para o grupo estruturar o trabalho, divulgar o serviço e começar a dar as aulas, fatores que fizeram com que não chegassem a trabalhar com o público externo. Por outro lado, afirmamos que houve uma certa apropriação dos conceitos da economia solidária, pois foram os participantes do grupo que mantiveram a ideia da criação de um "fundo comum de solidariedade", ideia existente antes da divisão em três grupos e, a nosso ver, radicalmente solidária, de acordo com a qual cada grupo ajudaria o outro. Consideramos também emblemático o fato de o grupo ter se desfeito quando começaram as inscrições para o vestibular, o que denota uma implicação maior com o estudo, com o "poder estudar", do que com o trabalhar; não foi ao acaso que escolheram trabalhar no grupo de ensino. 
Em nossa opinião, o GPN foi o grupo que conseguiu produzir junto e durou mais tempo, pois agregava os conhecimentos técnicos e políticos necessários para o trabalho bemsucedido em grupos de autogestão. Nesse grupo havia Andreia, que ofereceu o conhecimento técnico para criar produtos por meio da reciclagem do papel, e havia organização e interesse do grupo em, desde o início, realizar discussões de cooperativismo. Dessa forma, consideramos que essa dupla apropriação - de domínio do labor e da internalização das concepções da economia solidária - fez o grupo se apropriar da autogestão e, consequentemente, do projeto da autonomia. Somado a esse duplo saber desenvolvido, outro fator importante foi a existência da encomenda da empresa multinacional, pois esta, como algo que vem de um grupo externo, simbolicamente atribuía existência e reconhecimento ao GPN. Entendemos, com o psicólogo social Ignácio Martín-Baró (2004), que a identidade coletiva de um grupo não é apenas dada pelo grupo, mas também é gerada pela relação com outros grupos. Corrobora com nossa afirmação o fato de que foi a partir da relação com a multinacional que o GPN viu a necessidade de assumir uma identidade (antes era apenas o "grupo do papel"), gerando assim novos significados para si e para seus fazeres. No entanto, por mais que a encomenda tenha sido muito comemorada, sua realização foi difícil. O pouco tempo para produzir a encomenda e a falta de articulação do grupo acabou por gerar um elevado desgaste nas relações de trabalho, fator este que pôde ser constatado nos relatos de grande parte dos integrantes desse grupo. Dessa forma, consideramos que o desgaste sofrido pelo GPN em produzir o material pedido enfraqueceu os laços do grupo e diminuiu a implicação pessoal com o projeto, levando à sua desagregação.

Outro fator que dificultou a continuidade dos grupos de trabalho diz respeito à própria natureza do espaço em que estavam: um cursinho pré-vestibular, um local eminentemente de passagem, de transição, de preparação para a entrada em outro espaço, a universidade. Portanto, a relação transitória entre os alunos (e cooperados) e os cursinhos populares pode gerar dificuldades para a implementação desse modelo de produção.

Em relação ao embate autonomia versus heteronomia, notamos que a hierarquização comumente observada nas relações de trabalho foi reproduzida muitas vezes nos grupos. Mesmo com uma proposta de ruptura do modelo de produção econômico hegemônico, trabalhar horizontalmente com a concepção de autogestão não se mostrou tarefa fácil. Nos grupos, com certa frequência, foi possível notar relações verticais de poder, tanto no processo de administração como no de produção. $O$ grupo de cursistas tendeu, inicialmente, a instituir uma espécie de "líder" e colocar alguém nesse lugar, constituindo um vínculo de dependência entre um suposto dirigente e os dirigidos. Tal comportamento, reprodutor da ordem instituída, aponta para o fato de que facilmente pode se estabelecer uma dependência do grupo cooperado em relação a seus técnicos, em que o fazer torna-se contingente ao saber e que há esse risco, como afirma Sato (1999), de o conhecimento da universidade colonizar os grupos cooperados, tornando-se os saberes desenvolvidos nesse espaço capturantes dos saberes populares. Risco não só de os grupos cooperados se colocarem em um lugar "inferior" em relação à equipe de estagiários, mas também de os estagiários ocuparem esse lugar de poder "superior", que está relacionado a seu saber oficial, reconhecido institucionalmente. Em relação à heteronomia que denunciamos, Castoriadis (2006) nos ensina que ela "[...] es incorporada en las instituciones heterónomas de la sociedad, y en primer lugar en la estructura psicosocial del individuo mismo, para quien la idea de un cuestionamiento de la Ley es una idea inconcebible" (p. 91). Ou seja, é como se houvesse um "círculo vicioso" que só fortalecesse a heteronomia social, em que ela é naturalizada e reproduzida socialmente. Somamos à heteronomia o fato de que na atual sociedade neoliberal, competitiva, é estimulada uma cultura individualista e vertical, em que as subjetividades são moduladas pela lógica competitiva do capital (Deleuze \& Guattari, 1976), a mesma que se pretende transgredir com a autogestão e a economia solidária.

No entanto, com o trabalho de grupo, como no processo do GPN, houve a tendência de romper a heteronomia, de destituir a obrigatoriedade da presença de um líder e apontar para 
novos tipos de organização de grupo. No GPN pôde ocorrer um processo de horizontalização, associativismo e autogestão, em que, nos termos de Guattari (1987), o grupo deixou de ser submetido para se tornar sujeito. Foi a possibilidade de o grupo reciclar e reinventar o mundo que permitiu romper com as relações de poder instituídas no trabalho e ocasionar mudanças em sua prática e em seu cotidiano. Ao focar o projeto nessa direção, não o entendemos mais como um "fracasso", mas sim como um êxito que expressa os frutos da economia solidária por meio da criação de modos de subjetivação em contraposição à lógica de pensamento do capitalismo. É baseado em processos como esse que discordamos da crítica de Sousa (2008) sobre a economia solidária, quando defende que esta "reatualiza" a lógica do capitalismo por estar economicamente atrelada a ele e não o supera. A autora apresenta lucidez ao afirmar que em muitas práticas da economia solidária se reproduzem práticas próprias do capitalismo, mas não ocorre apenas isso: mesmo que a economia solidária não tenha superado nem venha a superar o capitalismo, processos transformadores ocorrem nos coletivos autogestionados e transformam suas subjetividades e hábitos, colocando-os no caminho da busca da autonomia.

Contudo, para que o projeto possa cumprir seu objetivo de criar um dispositivo de geração de renda em cursinhos populares, proporcionando retorno financeiro de subsistência aos alunos participantes, algumas questões devem ser aprofundadas. É preciso garantir condições mínimas de trabalho, como: espaço físico de trabalho, capital para o investimento inicial, formação consistente em economia solidária, organização do tempo de trabalho e estudo do cursista e ampliação do tempo de implementação do projeto, com um planejamento que contemple o curto, o médio e o longo prazo. Aqui levantamos a questão: seria interessante concentrar os esforços em uma única frente de trabalho? Ao invés de constituir três grupos "frágeis", talvez fosse mais produtivo implementar apenas um. Por outro lado, a existência de um único grupo implicaria necessariamente a restrição a outras iniciativas, forçando os participantes a construírem um consenso e bloqueando o surgimento de potenciais talentos, como o de Andreia.

Para concluir, a problemática apresentada no cursinho em 2001 continua sendo uma questão relevante na atualidade. Mesmo com a criação de políticas públicas que contribuem para a democratização do acesso às universidades - como o Programa Universidade para Todos (ProUni) - e a expansão dos cursinhos populares, torna-se imperioso que o debate referente à geração de renda entre na pauta das discussões dos cursinhos alternativos e dos projetos governamentais de inserção de alunos de baixa renda no ensino superior. Além da distribuição de benefícios, é de suma importância garantir programas de geração de renda que acolham as dificuldades financeiras e permitam flexibilizar horários de trabalho do aluno, que garantam as condições necessárias para a conclusão de seus estudos, seja em um curso pré-vestibular, seja na universidade. Consideramos que nossa contribuição para essa temática foi apresentar algumas dificuldades enfrentadas ao experimentar o modelo da economia solidária em um cursinho popular, mas também mostrar possibilidades de transformação psicossocial por meio do trabalho em regime de autogestão.

\section{Referências Bibliográficas}

Baremblitt, G. (2002). Compêndio de análise institucional e outras correntes: teoria e prática. Belo Horizonte: Instituto Félix Guattari.

Carvalho, J. C. B. (2006). Os cursos pré-vestibulares comunitários e seus condicionantes pedagógicos. Cadernos de Pesquisa, 36 (128), 299-326.

Castoriadis, C. (1983). Socialismo ou barbárie: o conteúdo do socialismo. São Paulo: Brasiliense.

Castoriadis, C. (1992). O mundo fragmentado: as encruzilhadas do labirinto (3ae ed.). Rio de Janeiro: Paz e Terra. 
Castoriadis, C. (1994). Una sociedad a la deriva: conversación con Cornelius Castoriadis. Archipiélago: Cuadernos de crítica de la cultura, 17.

Castoriadis, C. (2006). Una sociedad a la deriva: entrevistas y debates (1974-1997). Buenos Aires: Katz.

Deleuze, G. \& Guattari, F. (1976). O anti-Édipo. Rio de Janeiro: Imago.

Guattari, F. (1987). Revolução molecular. São Paulo: Brasiliense.

Lechat, N. M. P. \& Barcelos, E. S. (2008). Autogestão: desafios políticos e metodológicos na incubação de empreendimentos econômicos solidários. Revista Katálysis, 11 (1), 96-104.

Lourau, R. (1979). El Estado y el inconsciente: ensayo de sociología política. Barcelona: Kairós.

Martín-Baró, I. (2004). El sistema, grupo y poder: psicología social desde Centroamérica II (5a ed., Colección Textos Universitarios, v. 10). San Salvador: Universidad Centroamericana José Simeón Cañas.

Mitrulis, E. \& Penin, S. T. S. (2006). Pré-vestibulares alternativos: da igualdade à equidade. Cadernos de Pesquisa, 36 (128), 269-298.

Nardi, H. C., Yates, D. B., Fernandes, J. M. \& Rodrigues, M. C. (2006). Subjetividade e solidariedade: a diversidade das formas de implicação dos jovens na economia solidária. Psicologia: Reflexão e Crítica, 19, (2), 320-328.

Oliveira, F. (2007). Os sentidos do cooperativismo de trabalho: as cooperativas de mão-de-obra à luz da vivência dos trabalhadores. Psicologia Ë Sociedade, 19 (edição especial 1), 75-83.

Saffiotti, A. (2008). Crise e transformação: um estudo sobre a experiência de alunos de baixa renda num cursinho popular. Dissertação de Mestrado, Departamento de Psicologia Social e do Trabalho, Instituto de Psicologia, Universidade de São Paulo, São Paulo.

Santos, M. A. P. (2006). Desafios na aquisição da identidade profissional por jovens universitários egressos de cursinho prévestibular popular. Dissertação de Mestrado, Departamento de Psicologia Social e do Trabalho, Instituto de Psicologia, Universidade de São Paulo, São Paulo.

Sato, L. (1999). Djunta-mon: o processo de construção de organizações cooperativas. Psicologia USP, 10 (2), 219. 225.

Sato, L. \& Esteves, E. G. (2002). Autogestão: possibilidade e ambiguidade de um processo organizativo peculiar. São Paulo: ADS-CUT.

Singer, P. A. \& Souza, A. R. (Orgs.). (2000). Economia solidária no Brasil: a autogestão como resposta ao desemprego. São Paulo: Contexto.

Singer, P. A. (2002). Introdução à economia solidária. São Paulo: Fundação Perseu Abramo.

Sousa, D. N. (2008). Reestruturação capitalista e trabalho: notas críticas acerca da economia solidária. Revista Katálysis, 11 (1), 53-60.

Spink, P. K. (1996). A organização como fenômeno psicossocial: notas para uma redefinição da psicologia do trabalho. Psicologia e Sociedade, 8 (1), 174-192.

Veronese, M. V. \& Guareschi, P. (2005). Possibilidades solidárias e emancipatórias do trabalho: campo fértil para a prática da psicologia social crítica. Psicologia $\mathcal{E}$ Sociedade, 17 (2), 58-69.

Yamamoto, B. \& Kaminakagura, I. E., Silva, J. C. B., Ackerman, K., Carvalho, L. S., Kohara, P. K. I., Eisenlohr, M. G. \& Kovács, M. J. (2006). Plantão psicológico no Curso Pré-Vestibular Psico-USP : uma intervenção possível em um cursinho popular. In C. Ramos, G. G. Silva \& S. Souza (Orgs.), Práticas psicológicas em instituições (pp. 388-403). São Paulo: Vetor.

\section{Endereço para correspondência}

fe_andres@yahoo.com.br, DomenicoH@usp.br

Recebido em: 08/10/2008

Revisado em: 11/05/2009

Aprovado em: 26/01/2010 